\title{
Determinação do estádio de dessecação em soja de hábito de crescimento indeterminado no Mato Grosso ${ }^{1}$
}

\author{
Determining the level of burndown in soybean genotype with indeterminate growth \\ habit in Mato Grosso
}

\author{
Miriam Hiroko Inoue ${ }^{2 *}$, Pedro Silvério Xavier Pereira ${ }^{3}$, Kassio Ferreira Mendes $^{4}$, Ronei Ben ${ }^{5}$, \\ Rivanildo Dallacort ${ }^{2}$, Janile Tamiozzo Mainardi ${ }^{6}$, Dejânia Vieira de Araújo ${ }^{2}$, Paulo Alberto \\ Conciani $^{5}$
}

Resumo - Para as cultivares de hábito indeterminado, não há relatos do momento mais adequado para realizar a aplicação da dessecação em pré-colheita. $\mathrm{O}$ trabalho teve como objetivo avaliar a influência da dessecação realizada em três épocas sobre a qualidade fisiológica e sanitária das sementes e características agronômicas da cultivar de hábito indeterminado SYN9074 RR, cultivada em três áreas simultaneamente. O delineamento experimental utilizado foi o de blocos casualizados, com quatro tratamentos e quatro repetições, sendo realizada análise conjunta para três áreas distintas. Os tratamentos referem-se a diferentes épocas de aplicação de diquat $\left(0,3 \mathrm{~kg} \mathrm{ha}^{-1}\right)$, ou seja, em plantas de soja nos estádios de maturação R6.5 (sementes totalmente formadas, vagens 50\% amareladas e 50\% verdes), R7 (vagens 70\% amareladas, com uma vagem totalmente madura na haste principal), R7.5 (vagens $90 \%$ amareladas) e testemunha sem aplicação. Realizaram-se testes de germinação, massa seca da parte aérea e radícula, comprimento da parte aérea e radícula, sanidade e massa de 1000 sementes e produtividade de grãos. O estádio mais adequado para realizar a dessecação em pré-colheita da cultivar de soja de hábito indeterminado SYN-9074 RR foi com plantas apresentando 90\% de amarelecimento das vagens, ou estádio de maturação R7.5, o qual proporcionou maior produtividade e o menor índice de incidência de fungos Phoma sp., Colletotrichum dematium var. truncata e Fusarium sp.

Palavras chaves: Glycine max; produtividade; qualidade fisiológica; qualidade sanitária; sementes.

\footnotetext{
* Autor para correspondência

${ }^{1}$ Recebido para publicação em 17/10/2011 e aceito 02/03/2012.

2 Docentes do Departamento de Agronomia da Universidade do Estado de Mato Grosso (UNEMAT), Rodovia MT 358, Km 7, 78300-000, Tangará da Serra, MT. E-mail: <miriamhinoue@ hotmail.com>;

${ }^{3}$ Mestrando do Programa de Pós-Graduação em Agricultura Tropical da Universidade Federal de Mato Grosso (UFMT), Cuiabá, MT;

${ }^{4}$ Mestrando do Programa de Pós-Graduação em Agronomia (Produção Vegetal) da Universidade Federal de Viçosa (UFV), Rio Paranaíba, MG;

${ }^{5}$ Discentes do curso de Agronomia da Universidade do Estado de Mato Grosso (UNEMAT), Tangará da Serra, MT

${ }^{6}$ Mestranda do Programa de Pós-Graduação em Agronomia (Produção Vegetal) Universidade Estadual de Mato Grosso do Sul (UEMS), Aquidauana, MS;
} 


\begin{abstract}
For cultivars with indeterminate habit, there are no reports of the most appropriate period to conducted burndown in pre-harvest. The study aimed to evaluate the influence of burndown on three different times over physiological and sanitary quality of seeds and agronomic characteristics of SYN-9074 RR cultivar with indeterminate habit, in three areas simultaneously. It was used a randomized complete block design with four replications, and joint analysis were conducted for the three distinct areas. Treatments refer to the application period of diquat $\left(0.3 \mathrm{~kg} \mathrm{ha}^{-1}\right)$, or better, in soybean plants at maturation stages R6.5 (fully formed seeds, pods $50 \%$ yellow and $50 \%$ green), R7 (pods $70 \%$ yellow, with a fully mature pod on the main stem) and R7.5 (90\% yellow pods) and a check without herbicide. Germination test, dry mass of dossel and little root part, shoot length and little root, sanitary condition and mass of 1000 seeds and yield were evaluated. The period more adequate to accomplish burndown in pre harvest of SYN-9074 RR cultivar with indeterminate habit was with plants showing 90\% of yellow pods, or maturation period R7.5, that provided higher yield and lower incidence índex of Phoma sp., Colletotrichum dematium var. truncata and Fusarium sp. fungi.
\end{abstract}

Key words: Glycine max; yield; physiological quality; sanitary quality; seeds.

\section{Introdução}

A dessecação da soja é uma prática que tem como objetivo principal a antecipação de colheita para permitir a implantação do milho ou algodão safrinha. Segundo Kappes et al. (2009), a época mais favorável para dessecação em relação a qualidade fisiológica de sementes em soja de hábito determinado é o estádio R7.3.

A aplicação dos dessecantes é realizada quando a maioria das sementes atinge a maturidade fisiológica. Esta prática tem a finalidade de promover a secagem rápida das plantas e o aumento na uniformidade de maturação, possibilitando maior facilidade e rapidez na colheita, a obtenção de menor teor de impurezas e sementes de melhor qualidade, além da redução de perdas e menor custo de secagem (Inoue et al., 2003).

Segundo Lacerda et al. (2003a), dependendo da maneira como a dessecação é realizada (tipo, modo de ação e época em que o dessecante é aplicado), a qualidade das sementes pode ser afetada, inviabilizando sua utilização tanto para sementes quanto para grãos. Contudo, se a aplicação for realizada de maneira adequada, poderá haver maior uniformidade na maturação da lavoura, antecipar a colheita em alguns dias e ainda obter sementes com maior qualidade fisiológica e sanitária.

Trabalhos conduzidos por Lacerda et al. (2003b) com soja de hábito determinado, indicaram que os dessecantes paraquat, diquat e paraquat + diquat não afetaram o teor da fração lipídica dos grãos de soja. Maciel et al. (2005) relatam que a dessecação facilita o trabalho das colhedoras e permite a antecipação da colheita, reduzindo os prejuízos de fungos e insetos que incidem sobre a cultura da soja no final do ciclo. De maneira geral, a aplicação de dessecante em soja demonstra a possibilidade da antecipação da colheita, dependendo principalmente da época e eficácia da aplicação (Gomes et al., 2003). Dentro deste contexto, o herbicida Reglone ${ }^{\circledR}$ (diquat) apresenta ação de contato muito eficaz na dessecação da soja, uniformizando as plantas para uma melhor e mais eficiente colheita (Rodrigues \& Almeida, 1998). 
Particularmente para as cultivares de hábito indeterminado, não há relatos do momento mais adequado para aplicação da dessecação em pré-colheita. Tal fato assume maior importância diante da maturação desuniforme que essas plantas apresentam, aliada a crescente adoção de cultivo dessas cultivares, principalmente na região CentroOeste do Brasil.

Portanto, o objetivo desse trabalho foi avaliar a influência da dessecação de diquat em pré-colheita, realizada em três épocas e áreas simultaneamente, sobre a qualidade fisiológica e sanitária das sementes e características agrônomicas da cultivar de hábito indeterminado SYN-9074 RR.

\section{Material e Métodos}

O trabalho foi realizado em duas etapas, a primeira inicialmente a campo e a segunda em laboratório. A etapa de campo foi conduzida simultaneamente em três áreas. A área denominada como 1 encontra-se na Fazenda Tapejara, distrito de Deciolândia, pertencente ao município de Diamantino - MT, e localizada a $14^{\circ} 13^{\prime} 03^{\prime \prime} \mathrm{S}$ e $57^{\circ} 30^{\prime} 82^{\prime}$ ' W, com altitude média de $645 \mathrm{~m}$. A área 2 foi conduzida na Fazenda Jatobá, distrito de Deciolândia, a $14^{\circ} 13^{\prime} 03$ " S e 57 30'82" W, com altitude média de 645. A área 3 foi instalada no Campus Experimental do IFMT, em Campo Novo dos Parecis - MT, a $13^{\circ} 40^{\prime} 31^{\prime \prime} \mathrm{S}$ e $57^{\circ} 48^{\prime} \mathrm{W}$, com altitude média de $570 \mathrm{~m}$.

Em cada experimento, foram avaliados
quatro tratamentos conduzidos no
delineamento em blocos casualizados, com
quatro repetições. As parcelas experimentais
foram constituídas por oito linhas com $5 \mathrm{~m}$,
espaçadas de $0,5 \mathrm{~m}$ entre si.

Os tratamentos constituíram de três épocas de aplicação de diquat $\left(0,3 \mathrm{~kg} \mathrm{ha}^{-1}\right)$, quando as plantas de soja apresentavam-se nos estádios de maturação R6.5 (sementes totalmente formadas, vagens $50 \%$ amareladas e $50 \%$ verdes), R7 (vagens $70 \%$ amareladas, com uma vagem totalmente madura na haste principal) e R7.5 (vagens 90\% amareladas), além da testemunha sem aplicação. As aplicações de diquat foram realizadas com um pulverizador costal pressurizado por $\mathrm{CO}_{2}$, com bicos tipo leque XR110.02, mantidos à pressão de trabalho de $2,0 \mathrm{kgf} \mathrm{cm}^{-2}$, resultando em volume de calda de $200 \mathrm{~L} \mathrm{ha}^{-1}$. No momento da aplicação as condições climáticas das três áreas apresentavam-se com temperatura média de $35^{\circ} \mathrm{C}$ e umidade relativa superior a $60 \%$,

A cultivar de soja SYN-9074 RR, de hábito indeterminado, foi semeada nas três áreas no dia 09 de novembro de 2009, utilizando-se 17 plantas por metro, com população estimada em 340 mil plantas por hectare. A adubação foi realizada de acordo com as análises de solo de cada área. Os tratos culturais seguiram a recomendação da cultura (Souza \& Lobato, 2004). Portanto, não houve ocorrência de pragas, doenças ou sintomas de deficiência nutricional durante o ciclo da cultura nas três áreas, não interferindo assim no amarelecimento das vagens.

$\mathrm{Na}$ colheita foram eliminadas as duas fileiras externas, bem como $0,5 \mathrm{~m}$ de cada extremidade das linhas centrais como bordaduras. Essa operação foi realizada manualmente, três dias após a aplicação do dessecante. A testemunha foi colhida com 95\% das vagens apresentando coloração típica de vagens com maturidade completa, em R8 (Fehr \& Caviness, 1977). Após a colheita das plantas, a debulha foi realizada por meio de máquina trilhadeira estacionária. Em seguida, as sementes foram limpas com o auxílio de peneiras e secas em condições naturais, em local coberto durante sete dias. Após pesagem das sementes, os dados foram extrapolados para $\mathrm{kg} \mathrm{ha}^{-1}$. 
A avaliação da qualidade fisiológica e sanitária das sementes foi realizada no laboratório de Fitopatologia do Centro de Pesquisa, Ensino e Desenvolvimento Agroambiental da UNEMAT- Campus de Tangará da Serra-MT, por meio dos testes de germinação, massa seca da parte aérea e radícula e comprimento de parte aérea e radícula das plântulas, sanidade e massa de 1000 sementes.

O teste de germinação foi realizado com quatro sub-amostras de 50 sementes, utilizando como substrato papel toalha (tipo germitest) em forma de rolo, mantidos em germinador à temperatura constante de $25^{\circ} \mathrm{C} \pm$ $2^{\circ} \mathrm{C}$. O volume de água utilizado para umedecer o substrato foi equivalente a 2,5 vezes peso do papel seco (BRASIL, 2009). A avaliação foi realizada aos oito dias após a semeadura.

Foram separadas 10 plântulas ao acaso do teste de germinação, as quais foram utilizadas para a determinação do comprimento e massa seca da parte aérea e da radícula. Para isso, com auxílio de estilete, foi realizado um corte em cada plântula visando separar a parte aérea da parte radicular. $O$ comprimento da parte aérea e do sistema radicular foi medido com auxílio de régua milimetrada. A massa seca foi obtida após secagem da parte aérea e radícula em estufa de ventilação forçada, com temperatura de $65^{\circ} \mathrm{C}$. Após 72 horas nessas condições, foi realizado a pesagem, em gramas, utilizando-se balança semi-analítica, com precisão de três casas decimais.

$\mathrm{O}$ teste de sanidade foi determinado pelo método do papel de filtro (Neergaard, 1979) adaptado. Foram utilizadas oito repetições de 25 sementes dispostas em placas de petri de acrílico de $15 \mathrm{~cm}$, previamente desinfetadas, contendo papel filtro umedecido com água destilada e estéril, acrescida de diclorofenoxiacetato de sódio (2,4-D) a $0,5 \%$ e cerca de $15 \mathrm{~mL}$ de meio Agar. As placas foram incubadas a $23^{\circ} \mathrm{C} \pm 2^{\circ} \mathrm{C}$ com fotoperíodo de 12 horas durante sete dias. Para observação das sementes e identificação de fungos utilizado-se um microscópio estereoscópio. Após a identificação foi calculada a porcentagem de ocorrência de fungos nas sementes por tratamento.

Para a massa de mil sementes, foram contadas ao acaso, duas repetições com oito subamostras de 100 sementes, provenientes de amostras de sementes de cada tratamento. Com base na massa das subamostras, calculouse a média, a variância, o desvio padrão e o coeficiente de variação, para posteriormente obter o peso de 1000 sementes, onde o resultado foi expresso em gramas (BRASIL, 2009).

Os dados foram submetidos à análise de variância conjunta e, na presença de interação significativa, procederam-se os desdobramentos necessários. As médias dos tratamentos foram comparadas pelo teste de Tukey a 5\% de probabilidade. A análise conjunta dos dados foi realizada para as três áreas, uma vez que a razão entre o maior e o menor quadrado médio residual não foi superior a sete (Banzatto \& Kronka, 2006).

\section{Resultados e Discussão}

A análise conjunta dos dados revelou que a interação áreas $x$ tratamentos foi significativa $(p<0,05)$ para todas as características avaliadas, indicando que houve resposta diferencial entre as áreas de cultivo e as épocas de aplicação do dessecante.

As sementes provenientes da área 1 que receberam aplicação de dessecante quando 90\% das vagens estavam amareladas (T90\%), apresentaram maior porcentagem de germinação (Tabela 1). Tal fato também foi observado na área 3, apesar de não diferir significativamente da testemunha. 
Provavelmente quando $90 \%$ das vagens estavam amareladas as sementes já tinham atingido a sua maturidade fisiológica, concordando assim com os resultados obtidos por Kappes et al. (2009). Segundo esses autores, em virtude da maturidade fisiológica atingida pelas sementes de soja, a dessecação no estádio R7.3, aos 71 dias após o florescimento, foi a melhor época para essa prática, por ter apresentado os maiores índices de germinação.

Corroborando com os dados, Marcandalli et al. (2011), observaram que as sementes de duas cultivares de soja (MSOY 6101 e MG/BR 46), obtidas com aplicação de dessecantes (glifosato e paraquat) nos estádios R7 e R8 são de qualidade fisiológica superior às obtidas com aplicação no estádio R6, em relação à porcentagem de germinação, envelhecimento acelerado, comprimento de raiz de e condutividade elétrica.

No entanto, a maior porcentagem de germinação das sementes da área 2 foi verificada quando a dessecação foi realizada com $50 \%$ das vagens da maioria das plantas estavam amareladas (T50\%), em relação ao T90\% e à testemunha. Este resultado pode ser devido à precipitação pluviométrica $(25 \mathrm{~mm})$ que ocorreu no dia anterior da colheita das sementes provenientes do T90\%, realizada em 18 de fevereiro de 2010, que pode ter prejudicado a qualidade fisiológica das sementes (Figura 1). Resultados semelhantes foram obtidos por Lacerda et al. (2005), que também verificaram menor porcentagem de germinação nas sementes de soja obtidas na aplicação do dessecante, após o início do estádio R6 até o estádio R7, com 99\% das vagens marrons, sob ocorrência de chuvas de $13,8 \mathrm{~mm}$ no dia da colheita e de $24,2 \mathrm{~mm}$ no dia anterior.

Em relação às áreas, a maior média de germinação foi encontrada na área 1 com $61 \%$ de germinação (Tabela 1). Portanto, este valor não se enquadra no lote de padrão comercial. De acordo com as normas de produção de sementes vigentes no Brasil (BRASIL, 2005), a germinação mínima aceitável para comercialização de sementes de soja é de $80 \%$ para as categorias $\mathrm{C} 1$ e $\mathrm{C} 2$ de sementes certificadas.

Ao analisar as médias obtidas nas áreas para cada época de dessecação, evidencia-se que as sementes que não foram dessecadas (testemunha) apresentaram o menor percentual de germinação $(42,83 \%)$ (Tabela 1$)$.

Tabela 1. Médias da porcentagem de plântulas normais no teste de germinação de soja cultivar SYN-9074 RR, provenientes das três áreas. Safra 2009/2010.

\begin{tabular}{lcccc}
\hline \multicolumn{5}{c}{ Germinação $(\%)^{*}$} \\
\hline Trat. & Área 1 & Área 2 & Área 3 & Média \\
\hline $50 \%^{1 /}$ & $50,50 \mathrm{Bab}$ & $64,00 \mathrm{Aa}$ & $40,50 \mathrm{Bb}$ & 51,66 \\
$70 \%^{2 !}$ & $59,00 \mathrm{Ba}$ & $50,50 \mathrm{ABa}$ & $24,00 \mathrm{Bb}$ & 44,50 \\
$90 \%^{\frac{3}{\prime}}$ & $85,50 \mathrm{Aa}$ & $32,00 \mathrm{Bb}$ & $70,50 \mathrm{Aa}$ & 62,66 \\
Test. $^{4 \prime}$ & $49,00 \mathrm{Bb}$ & $9,00 \mathrm{Cc}$ & $70,50 \mathrm{Aa}$ & 42,83 \\
\hline Média & 61,00 & 38,87 & 51,37 & - \\
\hline
\end{tabular}

C.V. (\%) 20,31

*Médias com a mesma letra, maiúscula na coluna e minúscula na linha, não diferem entre si pelo teste de Tukey $(\mathrm{p} \leq 0,05) .{ }^{1 /}$ plantas com $50 \%$ das vagens amareladas (estádio R6.5); ${ }^{2 /}$ plantas com $70 \%$ das vagens amareladas (estádio R7.0); ${ }^{3 /}$ plantas com 90\% das vagens amareladas (estádio R7.5); ${ }^{4 /}$ testemunha sem aplicação. 


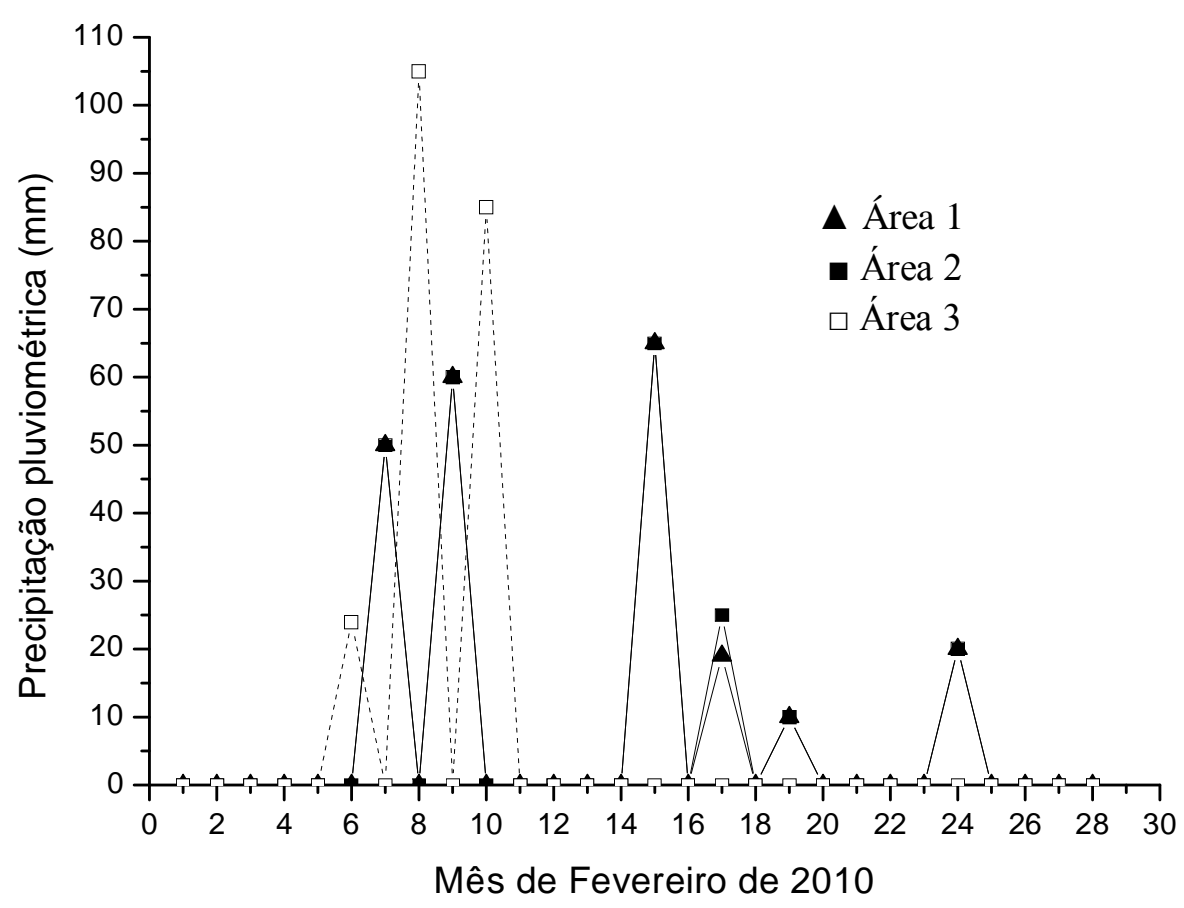

Figura 1. Valores de precipitação pluviométrica $(\mathrm{mm})$ em 24 horas coletados nas três áreas experimentais durante o mês de Fevereiro de 2010. As épocas de aplicação de diquat $\left(0,3 \mathrm{~kg} \mathrm{ha}^{-1}\right)$ nas três áreas, em plantas de soja nos estádios de maturação R6.5 (vagens 50\% amareladas), R7 (vagens 70\% amareladas ) e R7.5 (vagens 90\% amareladas), referem-se respectivamente, aos dias 05, 09 e 15 de Fevereiro de 2010.

Resultados semelhantes foram detectados por Peluzio et al. (2003), que também observaram queda na taxa de germinação de sementes com o atraso de colheita. A redução da capacidade de germinar é uma das consequiências do avanço do processo de deterioração das sementes (Perry, 1978). Corroborando com os dados Peluzio et al. (2008), também observaram que quanto maior o período de retardamento de colheita, para os estádios de desenvolvimento R6 e R8, menor foi à taxa de germinação.

O T50\% apresentou maior porcentagem de germinação na área 2 não diferindo significativamente da área 1 , que não diferiu da área 3. No T70\% ocorreu resultado semelhante, porém a porcentagem de germinação da área 1 foi superior a da área 3. No T90\% a área 1 apresentou maior porcentagem de germinação não diferindo significativamente da área 3 , que apresentou porcentagem de germinação superior a área 2. Na testemunha o melhor resultado obtido foi na área 3, sendo superior as áreas 1 e 2.

Nas áreas 1 e 2, sementes provenientes do T90\% apresentaram melhor desempenho na variável massa de 1000 sementes, em relação à testemunha (Tabela 2). No entanto, não houve diferença significativa entre os tratamentos para as sementes obtidas na área 3. Semelhantemente, Domingos et al. (2001) não observaram efeitos significativos na massa de 100 sementes e no rendimento das sementes de feijão cv. Carioca dessecadas com paraquat $\left(0,4 \mathrm{~kg} \mathrm{ha}^{-1}\right)$ e paraquat + diquat $(0,25+0,15$ $\left.\mathrm{kg} \mathrm{ha}^{-1}\right)$, de épocas de colheita em dois regimes 
de chuva simulada (ausência e presença) e duas modalidades de debulha (imediata à colheita e após enleiramento).

As médias de cada tratamento obtidas nas três áreas indicam que houve maior porcentagem de germinação e massa de 1000 sementes no T90\%. Segundo Kappes et al. (2009), a técnica da dessecação não diminui a germinação, podendo inclusive incrementar o poder germinativo das sementes. Do mesmo modo, Lacerda et al. (2005) relataram que quando a dessecação é efetuada de maneira adequada, esta operação pode resultar na obtenção de sementes com maior qualidade fisiológica.

No T50\% maior massa de 1000 sementes encontrado foi na área 2, porém não diferindo significativamente da área 3, que foi superior a área 1. Para T90\% o melhor resultado foi obtido na área 1 que não diferiu significativamente da área 2 , sendo que esta não diferiu da área 3. Já no T70\% e testemunha não ocorreram diferenças significativas nas áreas avaliadas (Tabela 2).

Tabela 2. Médias da massa de 1000 sementes e produtividade de soja da cultivar SYN-9074 RR, provenientes das três áreas. Safra 2009/2010. Produtividade de sementes de soja cultivar SYN9074 RR, provenientes das três áreas. Safra 2009/2010.

\begin{tabular}{|c|c|c|c|c|}
\hline \multicolumn{5}{|c|}{ Massa de 1000 sementes (g)* } \\
\hline Trat. & Área 1 & Área 2 & Área 3 & Média \\
\hline $50 \% \%^{\frac{1}{I}}$ & $105,03 \mathrm{Bb}$ & $114,10 \mathrm{ABa}$ & $113,39 \mathrm{Aa}$ & 110,84 \\
\hline $70 \%{ }^{2 \prime}$ & $109,03 \mathrm{Ba}$ & $115,47 \mathrm{ABa}$ & $109,55 \mathrm{Aa}$ & 111,35 \\
\hline $90 \%{ }^{3 /}$ & $122,78 \mathrm{Aa}$ & $116,33 \mathrm{Aab}$ & $113,75 \mathrm{Ab}$ & 117,62 \\
\hline Test. ${ }^{\prime \prime}$ & $101,95 \mathrm{Ba}$ & $107,15 \mathrm{Ba}$ & $109,31 \mathrm{Aa}$ & 106,14 \\
\hline Média & 109,70 & 113,26 & 111,50 & \\
\hline C.V. (\%) & & & & \\
\hline \multicolumn{5}{|c|}{ Produtividade $\left(\mathrm{kg} \mathrm{ha}^{-1}\right)^{*}$} \\
\hline Trat. & Área 1 & Área 2 & Área 3 & Média \\
\hline $50 \%{ }^{\frac{1}{}}$ & $1531,50 \mathrm{Cc}$ & $2537,10 \mathrm{Ba}$ & $2411,25 \mathrm{Bb}$ & 2159,95 \\
\hline $70 \%{ }^{\underline{2} l}$ & $2013,90 \mathrm{Bc}$ & $2429,55 \mathrm{Cb}$ & $2708,70 \mathrm{Aa}$ & 2384,05 \\
\hline $90 \%{ }^{3 /}$ & $2797,95 \mathrm{Aa}$ & $2712,00 \mathrm{Aa}$ & $2780,40 \mathrm{Aa}$ & 2763,45 \\
\hline Test. ${ }^{4}$ & $1282,95 \mathrm{Dc}$ & $2251,65 \mathrm{Db}$ & $2754,80 \mathrm{Aa}$ & 2096,46 \\
\hline Média & 1906,52 & 2482,57 & 2663,78 & \\
\hline C.V. (\%) & & & & \\
\hline
\end{tabular}

*Médias com a mesma letra, maiúscula na coluna e minúscula na linha, não diferem entre si pelo teste de Tukey $(\mathrm{p} \leq 0,05) . \stackrel{1 /}{ }$ plantas com $50 \%$ das vagens amareladas (estádio R6.5); $\stackrel{2 \prime}{\text { plantas }}$ com $70 \%$ das vagens amareladas (estádio R7.0); ${ }^{3 /}$ plantas com 90\% das vagens amareladas (estádio R7.5); ${ }^{4 /}$ testemunha sem aplicação.

Para as áreas 1 e 2, a maior produtividade de sementes foi obtida no T90\%, com rendimento superior a $2710 \mathrm{~kg} \mathrm{ha}^{-1}$ (Tabela 2). Na área 3, as parcelas que receberam o tratamento $\mathrm{T} 50 \%$ apresentaram rendimento inferior aos demais tratamentos (Tabela 2). Tal resultado pode ser atribuído ao fato das sementes ainda não estarem totalmente formadas, ou seja, não atingiram ainda o final da fase III (acúmulo de matéria seca), dos estádios de desenvolvimento das sementes (Marcos Filho, 2005).

O T90\% proporcionou ganho de produtividade de cerca de $21,84 \%, 13,73 \%$ e 
24,14\%, em relação aos T50\%, T70\% e à testemunha, respectivamente (Tabela 2). Contrariamente, Daltro et al. (2010), afirmaram que os produtos dessecantes utilizados (paraquat, diquat, paraquat+diquat, paraquat+diuron e glifosato), independentes do estádio em que foram aplicados, não interferiram no potencial produtivo das cultivares de soja no estado de Mato Grosso. Observou-se ainda que a produtividade média das áreas foi inferior a do estado de Mato Grosso que, em 2008 foi de $3082 \mathrm{~kg} \mathrm{ha}^{-1}$ (Conab, 2009).

Portanto, o uso de dessecantes promoveu a secagem e queda das folhas, além de reduzir a umidade das sementes rapidamente, possibilitando a realização da colheita em período mais próximo ao ponto de maturidade fisiológica, para que não ocorram perdas na produção (Lacerda et al., 2005).
No T50\% a maior produtividade foi obtida na área 2, sendo superior a área 3 e 1 respectivamente. No T70\% e testemunha a área 3 foi superior a área 2 e 1 respectivamente. No T90\% não ocorreu diferença significativa nas áreas avaliadas.

$\mathrm{Na}$ variável comprimento da radícula das plântulas de soja, o maior valor observado na área 1 foi para o $\mathrm{T} 90 \%$, diferindo significativamente da testemunha sem aplicação (Tabela 3). $\mathrm{Na}$ área 2, em comparação à testemunha, todos os tratamentos com aplicação de herbicida proporcionaram maior comprimento de radícula. Contudo, o comprimento de radícula das plântulas provenientes do tratamento $\mathrm{T} 70 \%$, obtidas na área 3, foram significativamente inferiores aos tratamentos T90\% e testemunha.

Tabela 3. Comprimento da radícula e da parte aérea das plântulas de soja cultivar SYN-9074 RR, provenientes das três áreas. Safra 2009/2010.

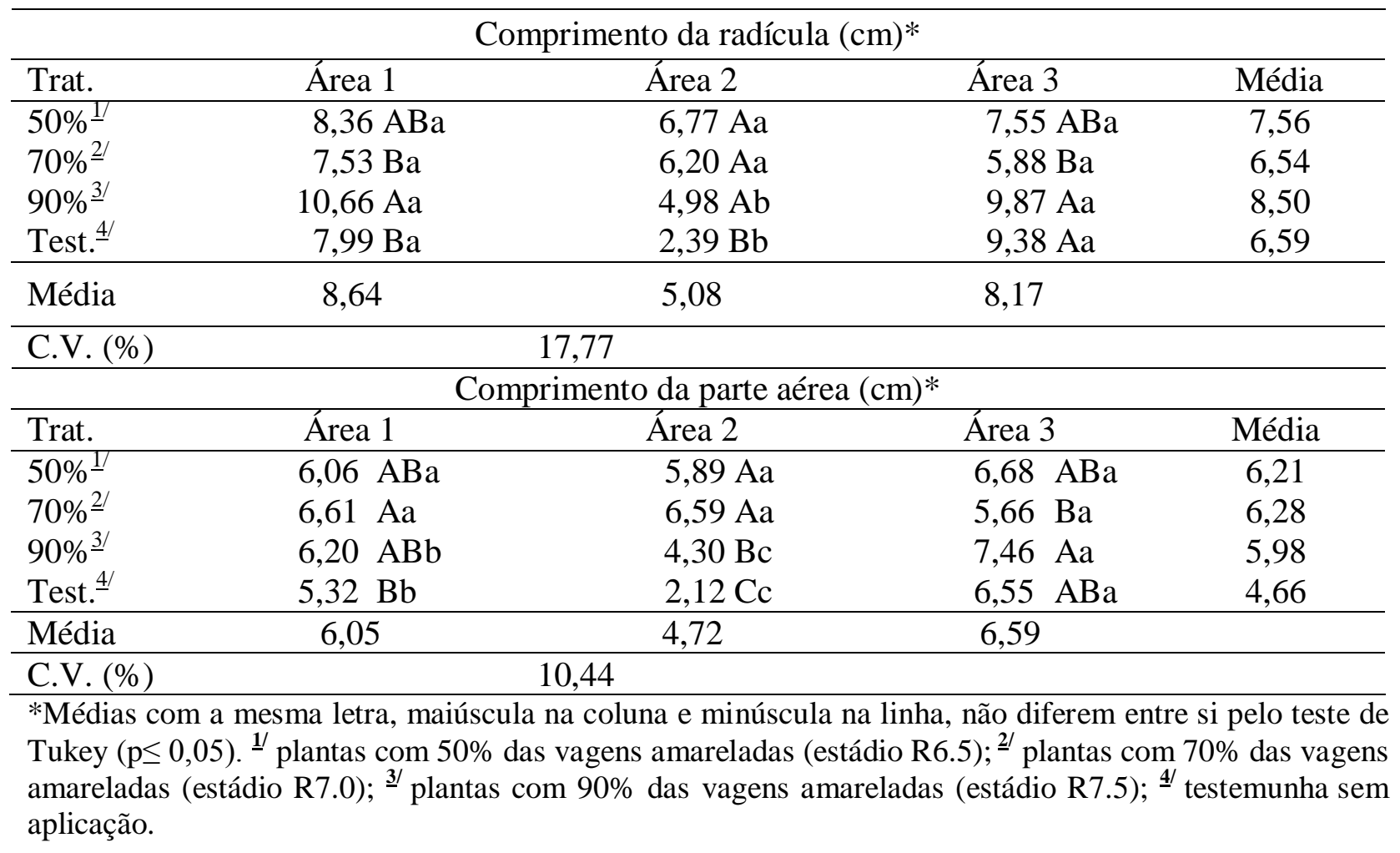


No T90\% e testemunha o maior comprimento da radícula foi na área 1 , porém não diferindo significativamente da área 3 , que por sua vez foi superior a área 2 (Tabela 3 ). $\mathrm{O}$ menor vigor das sementes de soja na área 2 esta de acordo com o observado para porcentagem de germinação, onde também observou-se redução, provavelmente em decorrência da chuva antes da colheita das sementes.

O T70\% foi significativamente superior à testemunha na variável comprimento de parte aérea das plântulas e não diferindo do T50\% e T90\%. Na área 2 T50 e T70\% proporcionaram maior comprimento de parte aérea das plântulas, em relação aos demais tratamentos (Tabela 3). $\mathrm{Na}$ área 3, o melhor resultado foi observado no $\mathrm{T} 90 \%$, sendo superior ao $\mathrm{T} 70 \%$. Ou seja, a dessecação da soja nas 3 diferentes áreas influenciaram de maneira distinta no vigor das sementes. Entretanto, para as áreas 1 e 2, comparativamente a testemunha, maior comprimento de radícula foi observado na dessecação da soja com $90 \%$ de amarelecimento das vagens. Para T50\% e T70\% não ocorreram diferenças significativas nas áreas avaliadas. Os comprimentos da parte aérea do $\mathrm{T} 90 \%$ e da testemunha foram superiores na área 3, em relação a área 1 e 2, que apresentaram resultados intermediários e inferiores, respectivamente .

Ao contrário de Daltro et al. (2010) que consideraram adequado o teste de comprimento de plântulas para a avaliação da qualidade fisiológica de sementes de soja, os resultados obtidos, permitiram constatar que esse teste não obteve os maiores comprimentos para o tratamento com $90 \%$ das vagens amareladas. Testes de comprimento de plântulas conduzidos por Daltro et al. (2010), utilizando sementes das cultivares 'Tucunaré' e 'Pintado', verificaram que a colheita antecipada proporcionou resultados superiores aos obtidos para a colheita normal. Vanzolini et al. (2007) também concluíram que o teste de comprimento de plântulas ou de suas partes é eficaz para detectar diferenças sutis de vigor em lotes de sementes de soja.

Para massa seca da radícula na área 1, a maior média foi verificada no T90\%, diferindo significativamente dos tratamentos $\mathrm{T} 70 \% \mathrm{e}$ testemunha (Tabela 4). No entanto, na área 3 o maior peso da radícula foi verificado na testemunha, a qual não diferiu significativamente do T90\%. Independente do tratamento, na área 2 as sementes não sofreram influência da dessecação (Tabela 4). Entretanto, na comparação entre as áreas para T90\% e testemunha, constata-se menor massa seca da radícula na área 2 em relação as demais. Corroborando novamente, com o observado nas variáveis germinação e comprimento de radícula e de parte aérea.

No T50\% não ocorreu diferença significativa entre as áreas avaliadas. Contudo, no $\mathrm{T} 70 \%$ os melhores resultados obtidos foram na área 1 e 2. Entretanto, no T90\% os melhores resultados encontrados foram na área 1 e 3, que por sua vez foram superiores a área 2. Já na testemunha o melhor resultado encontrado foi na área 3, sendo que na área 1 e 2 não ocorreram diferenças significativas entre ambas.

Para a variável massa seca da parte aérea, plântulas provenientes dos $\mathrm{T} 70 \%$ e T90\% na área 1 apresentaram maior massa, em relação aos demais tratamentos. $\mathrm{Na}$ área 2 todas as épocas de dessecação foram superiores à testemunha, ao passo que os tratamentos da área 3 não diferiram entre si (Tabela 4). 
Tabela 4. Massa seca da radícula e da parte aérea de soja cultivar SYN-9074 RR, provenientes das três áreas. Safra 2009/2010.

\begin{tabular}{|c|c|c|c|c|}
\hline \multicolumn{5}{|c|}{ Massa seca da radícula $(\mathrm{g})^{*}$} \\
\hline Trat. & Área 1 & Área 2 & Área 3 & Média \\
\hline $50 \%{ }^{\frac{1}{1}}$ & $0,110 \mathrm{ABa}$ & $0,093 \mathrm{Aa}$ & $0,102 \mathrm{Ba}$ & 0,1019 \\
\hline $70 \% \underline{2}$ & $0,106 \mathrm{Ba}$ & 0,096Aab & $0,074 \mathrm{Cb}$ & 0,0924 \\
\hline $90 \%^{\underline{3} /}$ & $0,137 \mathrm{Aa}$ & $0,079 \mathrm{Ab}$ & $0,114 \mathrm{ABa}$ & 0,1105 \\
\hline Test..$^{4}$ & $0,085 \mathrm{Bb}$ & $0,088 \mathrm{Ab}$ & $0,130 \mathrm{Aa}$ & 0,1018 \\
\hline Média & 0,1101 & 0,0894 & 0,1055 & \\
\hline \multirow{2}{*}{\multicolumn{5}{|c|}{13,97}} \\
\hline \multicolumn{2}{|c|}{ Massa seca da parte aérea $(\mathrm{g})^{*}$} & & & \\
\hline Trat. & Área 1 & Área 2 & Área 3 & Média \\
\hline $50 \%{ }^{1 /}$ & $0,8814 \mathrm{Ba}$ & $0,8641 \mathrm{Aa}$ & $0,8469 \mathrm{Aa}$ & 0,8642 \\
\hline $70 \%$ ㄴ & $1,0849 \mathrm{Aa}$ & $0,8574 \mathrm{Ab}$ & $0,8605 \mathrm{Ab}$ & 0,9343 \\
\hline $90 \%{ }^{\underline{3} /}$ & $1,1982 \mathrm{Aa}$ & $0,9840 \mathrm{Ab}$ & $0,8923 \mathrm{Ab}$ & 1,0248 \\
\hline Test..$^{4 /}$ & $0,7566 \mathrm{Bab}$ & $0,6622 \mathrm{Bb}$ & $0,8388 \mathrm{Aa}$ & 0,7525 \\
\hline Média & 0,9803 & 0,8419 & 0,8596 & \\
\hline C.V. $(\%)$ & & & & \\
\hline
\end{tabular}

*Médias com a mesma letra, maiúscula na coluna e minúscula na linha, não diferem entre si pelo teste de Tukey $(\mathrm{p} \leq 0,05) .{ }^{1 /}$ plantas com $50 \%$ das vagens amareladas (estádio R6.5); ${ }^{2 /}$ plantas com $70 \%$ das vagens amareladas (estádio R7.0); ${ }^{3 /}$ plantas com 90\% das vagens amareladas (estádio R7.5); ${ }^{4 /}$ testemunha sem aplicação.

Nas análises sanitárias das sementes, em relação a infecção com o fungo Phoma sp., observou-se que T90\% foi o que proporcionou a menor incidência do fungo nas áreas 1 e 2 (Tabela 5). $\mathrm{Na}$ área 3 , a testemunha foi $\mathrm{o}$ tratamento que apresentou a menor incidência do fungo. Este fato pode ser explicado devido a não ocorrência de chuvas a partir do dia 10 de fevereiro, não interferindo no momento da colheita da testemunha, favorecendo assim a baixa incidência do fungo (Figura 1).

De modo geral, a área 2 apresentou maior de infecção das sementes, enquanto que o $\mathrm{T} 90 \%$ proporcionou o menor índice de infecção das sementes (Tabela 5).

No T50\% não ocorreu diferença significativa nas áreas avaliadas. No $\mathrm{T} 70 \%$ a maior incidência do fungo foi verificada na área 2, não diferindo estatisticamente da área 3 que também não diferiu da área 1 . No T90\% a maior incidência foi verificada na área 3, enquanto que as áreas 1 e 2 não diferiram entre si.

$\mathrm{Na}$ testemunha a maior incidência foi verificada na área 2 , enquanto que a área 1 apresentou maior incidência do que na área 3.

Em relação ao Colletotrichum dematium var. truncata, ocorreu baixa incidência do patógeno nas sementes que receberam o $\mathrm{T} 90 \%$, sendo que na área 2 ocorreu baixa incidência em todos os tratamentos e foi a área menos afetada (Tabela 5). A partir dos dados da área 3 (Tabela 5), evidenciou-se que com aplicação realizada antes da maturidade fisiológica das sementes, houve aumento do potencial de infecção de fungos.

No $\mathrm{T} 50 \%$ e $\mathrm{T} 70 \%$ a maior incidência do fungo Colletotrichum dematium var. truncata foi verificada na área 3, enquanto que nas áreas 1 e 2 não ocorreram diferenças significativas entre ambas (Tabela 5). 
Tabela 5. Porcentagem de incidência de Phoma sp., Colletotrichum dematium var. truncata e Fusarium sp. em sementes de soja cultivar SYN-9074 RR, provenientes das três áreas. Safra 2009/2010.

\begin{tabular}{|c|c|c|c|c|}
\hline \multicolumn{5}{|c|}{ Phoma sp. $(\%)^{*}$} \\
\hline Trat. & Área 1 & Área 2 & Área 3 & Média \\
\hline $50 \%{ }^{\underline{1}}$ & $25,00 \mathrm{Aa}$ & $19,50 \mathrm{Ca}$ & $22,50 \mathrm{Aa}$ & 22,33 \\
\hline $70 \%{ }^{2 /}$ & $21,50 \mathrm{Ab}$ & $37,50 \mathrm{Ba}$ & $31,00 \mathrm{Aab}$ & 30,00 \\
\hline $90 \%{ }^{3 /}$ & $4,00 \mathrm{Bb}$ & $8,00 \mathrm{Db}$ & $24,50 \mathrm{Aa}$ & 13,50 \\
\hline Test. ${ }^{4}$ & $31,00 \mathrm{Ab}$ & $52,50 \mathrm{Aa}$ & $11,00 \mathrm{Bc}$ & 31,50 \\
\hline Média & 20,37 & 29,37 & 22,25 & \\
\hline C.V. (\%) & & & & \\
\hline \multicolumn{5}{|c|}{$\begin{array}{l}45,54 \\
\text { Colletotrichum dematium var. truncata }(\%)^{*}\end{array}$} \\
\hline Trat. & Área 1 & Área 2 & Área 3 & Média \\
\hline $50 \%{ }^{1 /}$ & $5,00 \mathrm{Bb}$ & $3,50 \mathrm{Ab}$ & $20,00 \mathrm{Aa}$ & 9,50 \\
\hline $70 \%{ }^{\underline{2}}$ & $7,50 \mathrm{ABb}$ & $0,00 \mathrm{Ab}$ & $20,00 \mathrm{Aa}$ & 9,16 \\
\hline $90 \%{ }^{3 /}$ & $0,00 \mathrm{Ca}$ & $1,50 \mathrm{Aa}$ & $8,00 \mathrm{Ba}$ & 3,16 \\
\hline Test. ${ }^{4 /}$ & $12,50 \mathrm{Aa}$ & $1,00 \mathrm{Ab}$ & $5,00 \mathrm{Bab}$ & 6,16 \\
\hline Média & 6,25 & 1,50 & 13,25 & \\
\hline C.V. (\%) & & & & \\
\hline \multicolumn{5}{|c|}{ Fusarium sp. (\%)* } \\
\hline Trat. & Área 1 & Área 2 & Área 3 & Média \\
\hline $50 \%^{\frac{1}{I}}$ & $26,50 \mathrm{Aa}$ & $25,50 \mathrm{BCa}$ & $34,00 \mathrm{Aa}$ & 28,66 \\
\hline $70 \%{ }^{\underline{2}}$ & $22,50 \mathrm{Ab}$ & $36,50 \mathrm{Aa}$ & 28,50 Aab & 29,16 \\
\hline $90 \%{ }^{3 /}$ & $5,50 \mathrm{Bb}$ & $17,00 \mathrm{Cab}$ & $18,00 \mathrm{Ba}$ & 13,50 \\
\hline Test. ${ }^{4}$ & $17,50 \mathrm{Ab}$ & $35,50 \mathrm{ABa}$ & $15,00 \mathrm{Bb}$ & 22,66 \\
\hline Média & 18,00 & 28,62 & 23,87 & \\
\hline CV (\%) & \multicolumn{4}{|c|}{43,75} \\
\hline
\end{tabular}

*Médias com a mesma letra, maiúscula na coluna e minúscula na linha, não diferem entre si pelo teste de Tukey $(\mathrm{p} \leq 0,05) .{ }^{1 /}$ plantas com $50 \%$ das vagens amareladas (estádio R6.5); ${ }^{2}$ plantas com $70 \%$ das vagens amareladas (estádio R7.0); $\stackrel{3}{\text { / }}$ plantas com 90\% das vagens amareladas (estádio R7.5); ${ }^{\stackrel{4}{ }}$ testemunha sem aplicação.

No T90\% não ocorreu diferença significativa nas áreas avaliadas. Já na testemunha a maior incidência do fungo foi na área 1, porém não ocorreu diferença significativa com a área 3, que também não diferiu da área 2. De acordo com Braccini et al. (2003), há considerável diferença de comportamento entre as cultivares de soja quanto à tolerância ao retardamento da colheita. O retardamento da colheita provocou redução na porcentagem de germinação, em decorrência do avanço do processo de deterioração das sementes, porém, com intensidades diferentes para as cultivares de soja. Além disso, os autores ainda relataram que a redução na germinação e vigor das sementes com o retardamento da colheita esteve associada ao aumento na porcentagem de sementes infectadas por microorganismos.

A menor incidência de Fusarium sp. na área 1 foi observada nas sementes que receberam o T90\%. Resultado semelhante foi observado na área 2, em que o T90\% proporcionou menor incidência do fungo, em 
relação ao T70\% e à testemunha (Tabela 5). Em relação aos demais tratamentos químicos, sementes provenientes do T90\% também apresentaram a menor incidência do patógeno na área 3.

A partir das médias apresentadas na Tabela 5, verifica-se que T90\%, aliado a área 1, apresentaram a menor incidência de Fusarium sp. nas sementes, em relação aos demais tratamentos. Braccini et al. (2003), avaliando 15 cultivares de soja verificaram que à medida que as sementes foram mantidas no campo após o estádio de maturação R8, ocorreu aumento na proporção de sementes infectadas por patógenos.

Entre as médias de incidência de Fusarium sp. nas três áreas avaliadas, a maior incidência ocorreu na área 2 no T70\%, com $36,50 \%$ e menor na área 1 no T90\% com $5,50 \%$. Estes resultados corroboram com os observados por Hamawaki (2002), em que o genótipo de soja FT-20 apresentou a maior incidência de $F$. semitectum $(35,17 \%)$ e o FT2001 a menor incidência $(6,55 \%)$.

No T50\% não ocorreu diferença significativa nas áreas avaliadas. No $\mathrm{T} 70 \%$ a maior incidência de Fusarium sp. foi encontrada na área 2, porém não diferiu significativamente da área 3 , que por sua vez não diferiu da área 1. No T90\% a maior incidência do fungo foi na área 3, porém não diferiu significativamente das áreas 2 e $1 . \mathrm{Na}$ testemunha a maior incidência foi na área 2 , enquanto que na área 1 e 3 não diferiram significativamente entre si.

\section{Conclusões}

O estádio mais adequado para realizar a dessecação em pré-colheita da cultivar de soja de hábito indeterminado SYN-9074 RR foi com plantas apresentando $90 \%$ de amarelecimento das vagens, ou estádio de maturação R7.5, o qual proporcionou maior produtividade e o menor índice de incidência de fungos Phoma sp., Colletotrichum dematium var. truncata e Fusarium sp.

\section{Referências}

BANZATTO, D.A., KRONKA, S.N. Experimentação agrícola. 4. ed. Jaboticabal: FUNEP, 2006. 237p.

BRACCINI, A.L. et al. Qualidade fisiológica e sanitária das sementes de quinze cultivares de soja (Glycine $\max$ (L.) Merrill) colhidas na época normal e após o retardamento da colheita. Acta Scientiarum Agronomy, v.25, n.2, p.449-457, 2003.

BRASIL. Instrução normativa $\mathrm{n}^{\mathrm{o}} 25$, de 16 de dezembro de 2005: Padrões para produção e comercialização de sementes de soja. Diário Oficial da União, Brasília, DF, n.243, 20 dez. 2005. Seção 1, p.2.

BRASIL, Ministério da Agricultura e da Reforma Agrária. Regras para análise de sementes. Brasília: SNDA/DNDV/CLAV, 2009. 365p.

CONAB, Companhia Nacional de Abastecimento. Acompanhamento de safra brasileira: grãos, décimo segundo levantamento, setembro/2009. Brasília: CONAB, 2009. 39p.

DALTRO, E.M.F. et al. Aplicação de dessecantes em pré-colheita: Efeito na qualidade fisiológica de sementes de soja. Revista Brasileira de Sementes, v.32, n.1, p.111-122, 2010.

DOMINGOS, M. et al. Efeitos de dessecantes, na época de colheita, do enleiramento e da chuva simulada no rendimento e na qualidade fisiológica da sementes de feijão. Revista Ceres, v.48, n.277, p.365-380, 2001.

FEHR, W.R.; CAVINESS, C.E. Stages on soybean development. Ames: Iowa State 
University/Cooperative Extention Service, 1977. 11p.

GOMES, J.C. et al. Efeito do dessecante paraquat na qualidade da fração lipídica da soja. Ciência e Agrotecnologia, v.27, n.1, p.178-184, 2003.

HAMAWAKI, O.T. et al. Avaliação da qualidade fisiológica e sanitária de sementes de genótipos de soja do ciclo precoce/médio em Uberlândia, Minas Gerais. Fitopatologia Brasileira, v.27, n.2, p.201-205, 2002.

INOUE, M.H. et al. Rendimento de grãos e qualidade de sementes de soja após a aplicação de herbicidas dessecantes. Ciência Rural, v.33, n.4, p.769-770, 2003.

KAPPES, C.; CARVALHO, M.A.C, YAMASHITA, O.M. Potencial fisiológico de sementes de soja dessecadas com diquat e paraquat. Scientia Agraria, v.10, n.1, p.1-6, 2009.

LACERDA, A.L.S. et al. Armazenamento de sementes de soja dessecadas e Avaliação da qualidade fisiológica, bioquímica e sanitária. Revista Brasileira de Sementes, v.25, n.2, p.97-105, 2003a.

LACERDA, A.L.S. et al. Aplicação de dessecantes na cultura de soja: teor de umidade nas sementes e biomassa nas plantas. Planta Daninha, v.21, n.3, p.427-434, 2003 b.

LACERDA, A.L.S. et al. Efeitos da dessecação de plantas de soja no potencial fisiológico e sanitário das sementes. Tecnologia de Sementes. Bragantia, v.64, n.3, p.447-457, 2005.

MACIEL, C.D.G. et al. Uso de Adjuvantes na dessecação da cultura da Soja: qualidade fisiológica de sementes. Revista Científica Eletrônica de Agronomia, v.4, n.7, p.1-5, 2005.

MARCANDALLI, L.H.; LAZARINI, E.; MALASPINA, I.C. Épocas de aplicação de dessecantes na cultura da soja: qualidade fisiológica de sementes. Revista Brasileira de Sementes, v.33, n.2, p.241-250, 2011.

MARCOS FILHO, J. Fisiologia de sementes de plantas cultivadas. Piracicaba: FEALQ, 2005. 495p.

NEERGAARD, P. Seed Pathology, London The MacMillan Press, v.1, 1979.

PELUZIO, J.M. et al. Qualidade de sementes de soja em diferentes épocas de colheita no sul do Estado do Tocantins. Revista Ceres, v.50, n.289, p.347-45, 2003.

PELUZIO, J.M. et al. Influência da dessecação química e retardamento de colheita na qualidade fisiológica de sementes de soja no sul do estado do Tocantins. Bioscience Journal, v.24, n.2, p.77-82, 2008.

PERRY, D.A. Report of the vigour committee, 1974-1978. Seed Science \& Technology, v.6, n.1, p.159-181, 1978.

RODRIGUES, B.N.; ALMEIDA, F.S. de. Guia de herbicidas. Edição dos Autores. Londrina:1998, 648p.

SOUZA, D.M.G.; LOBATO, E. Cerrado: correção do solo e adubação. 2. ed. Brasília: Embrapa Informação Tecnológica, 2004, 416p.

VANZOLINI, S. et al. Teste de comprimento de plântula na avaliação da qualidade fisiológica de sementes de soja. Revista Brasileira de Sementes, v.29, n.2, p.90-96, 2007. 